\title{
Optimization of Nanostructure Size on PDMS Surface to Improve Cell Interaction
}

\author{
Jueyu $\mathrm{Li}^{1}$, yuanyuan $\mathrm{Hu}^{1}$, Min Wang ${ }^{1}$ \\ ${ }^{1}$ Institute of Microanalytical Systems, Department of Chemistry, Zhejiang University, Hangzhou, China \\ minwang@zju.edu.cn
}

\begin{abstract}
Anodized aluminum oxide (AAO) was used as a template to create highly ordered nanostructures on polydimethylsiloxane (PDMS) surface. The PDMS with surface nanostructures was then applied for cell analysis. It was found that the size of the nanostructure had a deep effect on cell behavior. In this work, different nanopore size AAO was created either with different electrolytes or under different anodization potential. The imprinted PDMS was then used for cell culture to find the relationship between surface nano size and cell behavior.
\end{abstract}

Key words: PDMS, nanostructure, anodize potential, cell culture, AAO

\section{Introduction}

AAO was widely used as a template to create surface nanostructure. By pouring PDMS precursor and liquid stabilizer on the AAO template, nanostructure was easily copied to PDMS surface. Both the anodize potential and the electrolyte type can affect the nano pore size of the AAO template and thus the nano structures on PDMS. While the morphology of the nanostructures on PDMS has a deep influence on the proliferation and activity of cells [2] and bacterial adhesion [3].

\section{Experimental}

$0.3 \mathrm{~mol} / \mathrm{L}$ sulfuric acid, $0.3 \mathrm{~mol} / \mathrm{L}$ oxalic acid and $6 \%$ phosphate were chosen as the different electrolytes. The anodization potential was $60 \mathrm{~V}$.

While comparing the effect of different anodization potentials, $0.6 \% \quad \mathrm{H}_{3} \mathrm{PO}_{4}$ solution was selected as the electrolyte, and the oxidation time was one hour with the different potentials: $60 \mathrm{~V}, 80 \mathrm{~V}, 100 \mathrm{~V}, 120 \mathrm{~V}$ and $140 \mathrm{~V}$.

PDMS precursor and liquid stabilizer with a volume ratio of 10:1 were mixed. Then the PDMS mixture was poured onto the AAO template, cured in vacuum drying at $75^{\circ} \mathrm{C}$ for 1 $\mathrm{h}$ and carefully peeled off from the template. Then SKOV-3 or C6 cell were cultured on different PDMS surfaces and cell proliferation was counted. Cell activity was evaluated by MTT method.

\section{The Influence of Different Electrolytes}

AAO template was created in different electrolyte solution including $0.3 \mathrm{~mol} / \mathrm{L}$ sulfuric acid, $0.3 \mathrm{~mol} / \mathrm{L}$ oxalic acid and $6 \%$ phosphate.

The sizes of differently obtained PDMS nanostructures under the current experimental condition are $36.45 \mathrm{~nm}\left(\mathrm{H}_{2} \mathrm{SO}_{4}\right), 68.61 \mathrm{~nm}$ $\left(\mathrm{H}_{2} \mathrm{C}_{2} \mathrm{O}_{4}\right), 85.31 \mathrm{~nm}\left(6 \% \mathrm{H}_{3} \mathrm{PO}_{4}\right)$ each. C6 culture was carried out on these PDMS substrates and cell proliferation was counted and presented in Fig.1. Each data was the average of 10 parallel results

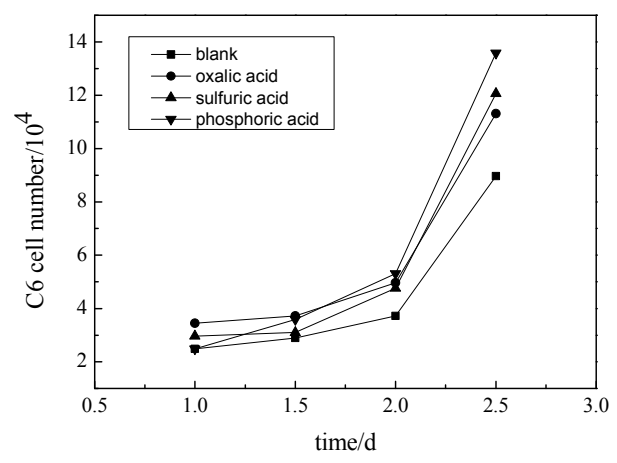

Fig.1: The effect on cell proliferation on imprinted $P D M S$ from $A A O$ with different electrolytes

Cell proliferation on substrates with nanotopography was greater than that on planar substrate. And according to Fig. 1, the nanostructure which was copied from phosphate electrolyte was the best for the proliferation of $\mathrm{C} 6$ cells. It may be due to the larger nano structure on the surface of PDMS 
that copied from $\mathrm{H}_{3} \mathrm{PO}_{4}$ anodized AAO template. Too small size of the nanostructures will not match the size of cells very well.

\section{The Influence of Anodize Potential on the Size of Nano Structure on PDMS Surface}

According to the result above, in the experiment, $\mathrm{H}_{3} \mathrm{PO}_{4}$ was chosen as the electrolyte. Anodize potential was controlled to achieve different sizes of nanostructures of the AAO template. The scale of nanostructure copied from AAO template to PDMS surface was shown in table 1.

Tab. 1: The width of nano structures on PDMS copied from AAO templates anodized in different potentials.

\begin{tabular}{|c|c|c|c|c|c|}
\hline Potential (V) & 60 & 80 & 100 & 120 & 140 \\
\hline Width (nm) & 85.3 & 214.8 & 281.3 & 312.5 & 351.6 \\
\hline
\end{tabular}

\section{The Influence of Different Nano Scale to SKOV-3 Cells}

SKOV-3 cell culture was carried out on differently treated PDMS to examine the effect of different nanostructure on cell behavior.

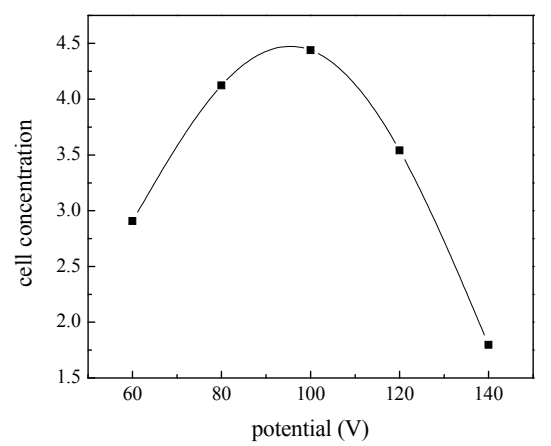

Fig. 2: SKOV-3 cell proliferation results for $48 \mathrm{~h}$ on differently treated PDMS. Unit: $10^{4}$ cells $\bullet \mathrm{mL}^{-1}$.

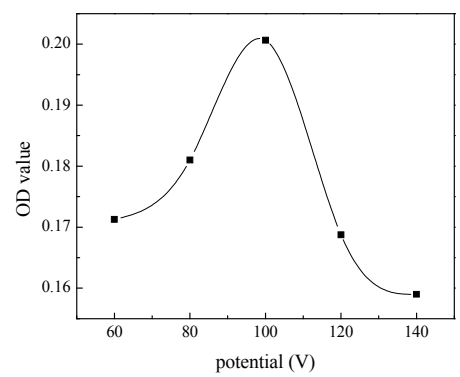

Fig. 3: MTT results of SKOV-3 cell activity for $48 \mathrm{~h}$ on differently treated PDMS.

The number of cells in each well was counted according to cell density. Cell proliferation numbers for $48 \mathrm{~h}$ culture on these PDMS were averaged by five samples as shown in Fig. 2 . For MTT test, the $48 \mathrm{~h}$ culture result was recorded. Each data was the average of 10 parallel results (Fig. 3). Both results showed that in the condition of $100 \mathrm{~V}$ potential, cell growth was the best.

The $281.3 \mathrm{~nm}$ structure, which was gained at the potential of $100 \mathrm{~V}$ was the best condition for SKOV-3 cell culture. It may be explained that this scale can cause cell tentacles to get the most favorable adsorption, so that the cells can stretch best and has the highest vitality. On the other hand, if the nanostructure gets too large, the promoting of cell growth will decrease.

\section{Conclusion}

The experiment shows different electrolytes and anodization potential will lead to different nanostructures of AAO template and thus affect the nanostructure on PDMS surface. The nano scale of PDMS can greatly influence the culture of the cells. Among all the electrolytes, phosphate acid was the best. And as the anodize potential increased, nano scale on the PDMS surface became larger, the cell growth condition reached the best while the potential is $100 \mathrm{~V}$. The result showed that the nanostructure which gained under $100 \mathrm{~V}$ with phosphate acid as the electrolyte match the size of cells best. The further study of this research can be done with different cell types. The optimized nano scale can be integrated into microfluidic channels and applied in cell enrichment or cell screening.

\section{Acknowledgements}

This project was sponsored by Zhejiang Provincial Natural Science Foundation of China under Grant No. Z4110019, the National Science Foundation of China under Grant No. 20890020, and the Fundamental Research Funds for the Central Universities.

\section{References}

[1] M. Wang, Y. Lu, Nano patterned PDMS for periodontal ligament fibroblast culture, Surface and Coating Technology 204, 525-530 (2009); doi:10.1016/j.surfcoat.2009.08.035

[2] H. Choi H, K. Koo, S. Park, M. Jeong, G. Kim, J. Park, J. Lim, W. Chung, S. Lee, S. Jin, Y. Lee, T. H. Park, J. Y. Yoo, D. D. Cho, Improvement of bacterial tethering using both physical and chemical surface modification for flagella spin actuators Sensors and Actuators B 123, 269-276 (2007); doi:10.1016/j.snb.2006.08.019 